\title{
Chronic Fatigue Syndrome in Canadian Adults: Profiling Demographic and Socioeconomic Factors, Mental Health Diagnoses and Conditions, and Life Experiences
}

\author{
Alysha Renouf \\ Memorial University of Newfoundland \\ Ken Fowler ( $\nabla$ kenfowler@mun.ca ) \\ Memorial University of Newfoundland \\ Stacey Wareham-Fowler \\ Memorial University of Newfoundland
}

\section{Research Article}

Keywords: Chronic fatigue syndrome (CFS), demographic, socioeconomic, psychiatric, life history, Canadian adults

Posted Date: April 16th, 2021

DOI: https://doi.org/10.21203/rs.3.rs-408624/v1

License: (c) (1) This work is licensed under a Creative Commons Attribution 4.0 International License.

Read Full License 
CHRONIC FATIGUE SYNDROME IN CANADIAN ADULTS: PROFILING

DEMOGRAPHIC AND SOCIOECONOMIC FACTORS, MENTAL HEALTH DIAGNOSES AND CONDITIONS, AND LIFE EXPERIENCES

A. Renouf PsyD ${ }^{1}, *$ Ken Fowler $\mathrm{PhD}^{1}$, Stacey Wareham-Fowler PhD MD ${ }^{2}$

${ }^{1}$ Department of Psychology, Faculty of Science, Memorial University of Newfoundland, St.

John's, NL, Canada

${ }^{2}$ Division of Family Medicine, Faculty of Medicine, Memorial University of Newfoundland, St.

John’s, NL, Canada

Contact email: kenfowler@mun.ca

Keywords: Chronic Fatigue Syndrome; Demographic and Socioeconomics; Psychiatric Disorders; Posttraumatic Stress Disorder; Attention Deficit Hyperactive Disorder; Sleeping Troubles; Childhood Maltreatment 


\begin{abstract}
Background: Chronic fatigue syndrome (CFS) is a debilitating condition characterized by a complex assortment of biological, psychological, and functional issues. In the literature, while a debate persists in terms of CFS etiology and treatment options, very rudimentary queries also linger in terms of associated CFS demographic and socioeconomic characteristics, comorbid psychiatric diagnoses, and potentially deleterious life challenges and experiences which, if more definitively clarified, may help elucidate illness origin and management.

Methods: Using data extracted from the Canadian Community Health Survey - Mental Health (CCHS-MH) (Statistics Canada, 2013) for adults aged 20 to 64 years of age, the current study developed a descriptive statistical profile of demographic, socioeconomic, psychiatric, and life experience characteristics of Canadians reporting a diagnosis of CFS. Further, a series of twofactor Chi Square tests were carried out to determine whether featured variables were significantly more likely for CFS sufferers as compared to adult Canadians without a CFS diagnosis.
\end{abstract}

Results: It was observed that those reporting a CFS diagnosis were significantly more likely to be female, between the ages of 45-64, divorced or separated, living alone, unemployed or unable to work, and of relatively low personal income. CFS sufferers were also more likely to have comorbid psychiatric diagnoses including lifetime and 12-month Major Depressive Disorder (MDD), Generalized Anxiety Disorder (GAD), and substance dependence, as well as selfreported posttraumatic stress disorder (PTSD), attention deficit hyperactivity disorder (ADHD), sleeping troubles, and reported histories of childhood physical and sexual maltreatment.

Conclusions: A very compelling demographic, socioeconomic, psychiatric, and life history profile of CFS sufferers emerged in this study, corroborating many findings in the literature. 
Since this study involved a national assessment CFS across Canada, it may afford some lucidity and insight in terms of etiological implications, and hence more precision in diagnosis, and potentially innovative treatment options. Future topics of inquiry, and potential limitations are also considered. 


\section{Introduction}

The disease state known as chronic fatigue syndrome (CFS) has gone by many names, including myalgic encephalomyelitis, systemic exertion intolerance disease, Gulf War syndrome, historically as neurasthenia/nervous exhaustion, or simply medically unexplained symptoms [16]. Along with the changes in nomenclature, have come many iterations of diagnostic criteria (See Table 1 for selected criteria). As the name suggests, CFS results in significant mental and physical exhaustion on the part of the individual [7], specifically resulting in a 50 percent reduction in activity level [3]. However, sufferers may also experience a range of immune and gastrointestinal symptoms, energy production and transportation impairment, and neurological symptoms including pain, cognitive decline, sleep disturbances, and sensory concerns [3] which can last for decades [8], resulting in a significant disease burden for this population.

As the diagnostic criteria have varied over the years, it has been difficult to fully establish demographic and socioeconomic characteristics of individuals with CFS, with heterogeneous findings across the current body of literature. This is also evident in the variability of prevalence rates, ranging between 0.2 to 3.2 percent depending on the criteria used, and whether based on clinician-assessment or self-report $[9,10]$. Nonetheless, women have been found to be 1.5-2.7 times more likely to experience CFS $[11,12]$, and depending on symptom severity, and given CFS's pervasive nature, many are unable to maintain employment, may require reduced work hours, or are completely housebound [11, 13].

The limitations of employment and activity level have frequently been found to limit personal income capacity such that CFS is more often found within lower class households with an income discrepancy of $\$ 20,000$ per year, or with total household incomes less than $\$ 40,000$ per year $[10,12,14,15,16]$. 
Table 1 - Timeline of Selected CFS Diagnostic Criteria

\begin{tabular}{|c|c|c|}
\hline Author & Year & Criteria \\
\hline Holmes et al. [54] & 1988 & $\begin{array}{l}\text { Must have new onset of persistent or relapsing fatigue with no } \\
\text { previous history of similar symptoms that does not resolve with rest, } \\
\text { and impairs functioning below } 50 \% \text {, which is not better accounted } \\
\text { for by another condition. An additional } 8 \text { of following must be } \\
\text { present: mild fever, sore throat, painful lymph nodes, unexplained } \\
\text { muscle weakness, muscle discomfort/myalgia, prolonged fatigue } \\
\text { post-exercise, headaches, arthralgia without swelling or redness, } \\
\text { neuropsychologic complaints, sleep disturbance, development over } \\
\text { a few hours to a few days. Further, two of the following must also be } \\
\text { documented by a physician: fever, pharyngitis, tender lymph nodes. }\end{array}$ \\
\hline Fukuda et al. [55] & 1994 & $\begin{array}{l}\text { Chronic (persistent or relapsing) fatigue for a minimum of six } \\
\text { months, as well as four of the following: impaired } \\
\text { memory/concentration, sore throat, tender lymph nodes, muscle } \\
\text { pain, multi-joint pain, new headaches, unrefreshing sleep, post- } \\
\text { exertion malaise }\end{array}$ \\
\hline Carruthers et al. [56] & 2003 & $\begin{array}{l}\text { New onset, unexplained, persistent, or recurrent fatigue, post- } \\
\text { exertional malaise, sleep dysfunction, and pain. Additionally, at least } \\
\text { two cognitive symptoms, and at least one symptom from two of the } \\
\text { following categories: autonomic, neuroendocrine, immune } \\
\text { manifestations. }\end{array}$ \\
\hline Carruthers et al. [3] & 2011 & $\begin{array}{l}\text { Post-exertional exhaustion which lasts for a minimum of } 24 \text { hours, at } \\
\text { least one neurological impairment (cognitive, pain, sleep } \\
\text { disturbance, sensory/perceptual/motor), at least one } \\
\text { immune/gastrointestinal/genitourinary impairment, at least one } \\
\text { energy production/transportation impairment. }\end{array}$ \\
\hline
\end{tabular}

Note. Represents most commonly used definitions. Those which have not been used in the review of relevant literature have not been featured.

While it is unclear as to whether income limitations of individuals with CFS are a direct function of academic attainment levels, some evidence does suggest that the highest prevalence of CFS is among well-educated, white women [15]. However, this contention seems less reliable within the larger body of literature [17]. Regardless, the socioeconomic and employment 
challenges that seem highly associated with CFS often result in increased stigma which serves to exacerbate the severity of illness for sufferers $[10,12,14,15,16,17]$. This stigma is also perpetuated by the confusion surrounding the etiology of illness for this population.

While a number of possible causes have been explored, none have been able to independently account for the onset or maintenance of CFS. As such, it has been proposed that CFS be considered a set of symptoms rather than the result of one particular disease state [18]. Further, there is ongoing debate as to whether CFS might be best classified within the category in the DSM-5 of Somatic Symptom and Related Disorder (SSRD) [19]. This illness conceptualization captures the perspective that many healthcare professionals view CFS as a new label for medically unexplained somatic symptoms, whereby patients often continue to search for a medical cause in spite of continual negative findings [20]. However, this does not account for the numerous findings related to a biological origin of CFS.

With regard to a probable biological etiology, while 72 percent of individuals diagnosed with CFS believed their illness was related to a viral infection, only 33 percent were able to specifically verify such a history [7]. Viruses implicated in onset include enterovirus, EpsteinBarr virus, influenza, Hepatitis A, and toxoplasmosis, but such physical causes alone are insufficient to completely account for CFS onset and maintenance [21]. CFS sufferers have also been found to be immuno-compromised, have increased cellular stress linked to aging, as well as gastro-intestinal difficulties prior to the onset of illness [22]. Interestingly, in an effort to find a biomarker of CFS, an analysis of the electrical conduction of blood cells revealed that those with CFS had a significantly different electrical resistance pattern from a control group which may be unique to CFS [23]. While there have been findings of biological basis and physiological markers of illness, it is of particular interest that individuals who believe their CFS has a 
biological origin experience significantly more functional impairment than those who report other causes, such as psychological or social [8, 13, 24].

There has also been a focus on potential psychological influences with respect to the onset of CFS. Comorbidity of CFS with major depressive disorder (MDD), for instance, has led to suggestions that the manifestation of CFS is the experience of a psychiatric disorder primarily characterized by fatigue $[2,25]$. This interpretation stems from the overlap in physical symptoms seen in CFS and depressive mood disorders including fatigue, loss of energy, difficulty sleeping, and difficulty concentrating [19] but is perpetuated by several findings. Individuals with CFS, for example, have been found to present with significantly more symptoms of depression, and with greater symptom severity than individuals who are otherwise healthy, and those with autoimmune disorders [26]. Further, upon treatment, the remission of CFS symptoms often occurs in conjunction with remission of depressive symptoms, and the return of symptom severity of CFS occurs when depressive symptoms return [2].

Individuals with CFS also report significantly more traumatic life events, and greater perceived stress than non-CFS controls in the year leading up to onset and diagnosis [27, 28]. Sufferers are also more likely to report clinically significant symptoms of PTSD than non-CFS controls [27]. Also of particular interest is the prevalence of early childhood trauma in this population. Not only have those with CFS been found to be significantly more likely than the general public to report emotional, physical, and/or sexual trauma during childhood, but the presence of childhood trauma has repeatedly been observed to predict fatigue, fatigue severity, and overall symptom severity in this population $[27,28,30,31]$.

In addition to depressive and trauma-related disorders, several other psychiatric comorbidities have been implicated in the development and maintenance of CFS. Anxiety 
disorders, including social anxiety disorder and panic disorder have been observed to be significantly more prevalent among those with CFS than healthy controls, as well as individuals with other chronic health conditions [32, 33]. Attention-deficit/hyperactivity disorder (ADHD) has also been found to be significantly more prevalent among CFS sufferers, as well as substance-related disorders, and sleep-wake disorders [33, 34]. Further, a linear relationship between somatic and psychological symptoms has been demonstrated in individuals with CFS suggesting greater distress could result in increased severity of disease [25]. This finding would be consistent with the view of CFS as being possibly a SSRD whereby psychological distress presents in individuals as physiological symptoms [4]. However, not all individuals with CFS have a comorbid psychiatric disorder, and as such, this illness conceptualization has been insufficient in accounting for the prevalence of CFS $[2,25]$.

\section{Objectives and Rationale}

To the best of our knowledge, there has never been a nation-wide assessment in Canada or the U.S. of the prevalence, demographic, socioeconomic, mental health, and life experience characteristics of individuals reporting a diagnosis of CFS. It would appear that previous research has consisted of small samples, with the largest state-wide cohort study conducted in Georgia in the U.S. [16], and one meta-analysis examining prevalence related to differing diagnostic criteria [9].

Additionally, research findings have been variable in terms of factors such as sociodemographic characteristics representative of CFS individuals. Some studies, for instance, have indicated that those diagnosed CFS are more likely to be white, middle-upper class women, while others report that CFS is observed equally across race, with significant variability in findings for gender and socioeconomic status [11, 15, 12, 16, 17, 21]. 
Potential disagreement among researchers might be indicative of an underdeveloped appreciation of CFS, and specific characteristics those diagnosed with the disorder. Hence, in an effort to understand, diagnose, and better manage/treat CFS, this present study was designed to gain a better understanding of the population diagnosed with this disorder. Additionally, given the purported psychological involvement in the onset and maintenance of CFS, psychological comorbidities and influential life experiences are also explored.

\section{Method}

\section{Participants}

Participants in this study were selected from the Canadian Community Health Survey Mental Health 2012 (CCHS-MH), a national cross-sectional survey containing data from 25,113 individuals across the 10 Canadian provinces [35]. Individuals living in the Canadian territories and on First Nations reserves, full-time members of the Canadian Forces, and individuals who were institutionalized during data collection were excluded from this process. The Public Use Microdata File includes data on individuals aged 15 to 80 years of age and older. For this study, those aged 15 to 19 years, and 65 years and over were excluded as Canadian adults with CFS were of primary interest. Of the 25,113 individuals who completed the CCHS-MH, there were 16,972 respondents between the ages of 20-64. The target group involved individuals who disclosed they had been diagnosed with CFS by a health professional (See Reported Conditions section below for details). While self-reported, previous research suggests that it is very unlikely for individuals with CFS to self-diagnose, implicating the indicator's reliability [12].

\section{Data Collection}

Data were collected via the CCHS-MH questionnaire, using computer assisted interviewing to ensure participants were asked only those questions which would pertain to them 
based on previous answers [35]. Participants were selected using random-digit dialing across Canada using pre-selected regions. The majority of interviews were completed in person, with the remainder conducted by telephone.

\section{Materials}

Sociodemographic variables. Sociodemographic variables were categorical in nature and included gender (male, female), age (20-34, 35-44, 45-54, 55-64), race (white vs. nonwhite), marital status (married, divorced or separated, widowed, and single), household size (one-person or more), education (less than secondary school, secondary school graduation, some post-secondary, and post-secondary graduation), personal income in Canadian dollars (less than $\$ 10,000, \$ 10,000-\$ 19,999, \$ 20,000-\$ 29,999, \$ 30,000-\$ 39,999, \$ 40,000-\$ 49,999$, and $\$ 50,000$ and above), and employment status (i.e., whether respondent did not have a job, or was permanently unable to work).

\section{Assessment of psychiatric disorders-Lifetime and 12-month prevalence. The} questions used for the CCHS-MH modules on major depressive disorder (MDD), generalized anxiety disorder GAD, alcohol, cannabis, and substance dependence were based on a recognized World Health Organization version of the Composite International Diagnostic Interview (WHOCIDI) modified for the needs of CCHS-MH [35]. The WHO-CIDI is a standardized instrument for the assessment of mental disorders and conditions based on the definitions and criteria of Diagnostic and Statistical Manual of Mental Disorders (4th ed.; DSM-IV) [36] and International Classification of Diseases and Related Health Problems (ICD-10) [37]. Mental conditions or problems found in the CCHS-MH are partially coded to DSM-IV [35]. Computer-based algorithms were used to calculate lifetime criteria for each disorder based on respondents' answers to the questions within each disorder module. For each disorder, 12-month criteria 
included meeting the criteria for a lifetime diagnosis of the disorder, experiencing an episode of the disorder within the previous 12 months, and experiencing a marked impairment in occupational and social functioning.

Reported Conditions - Other conditions of interest were captured in the CCHS-MH by means of specific lines of questioning posed to respondents. For instance, to capture a diagnosis of CFS, as well as PTSD and ADHD, respondents were asked to confirm whether they had received a diagnosis by a health professional, and whether the condition was expected to last (or had already lasted) 6 months or more.

Problems with sleeping were assessed with the question "How often do you have trouble going to sleep or staying asleep?" While responses were rated on a 5-point scale from 1 (none of the time) to 5 (all of the time), a binary variable was created whereby participants who reported having trouble sleeping "most of the time" or "all of the time" were observed as experiencing insomnia.

In terms of childhood trauma, the CCHS-MH employed the Childhood experiences (CEX) questionnaire, a six question self-report scale used to measure the instances of physical and sexual violence before age 16 [38]. For the purposes of the present study, two binary variables were created. Specifically, respondents were classified as experiencing physical maltreatment if they reported at least one incident of being "slapped, hit or spanked", "pushed, grabbed, shoved or thrown”, or "physically attacked (i.e., kicked/ bitten/ punched/ choked/ burned/ other)" by an adult. Similarly, respondents were classified as experiencing sexual maltreatment if they reported at least one incident of "forced or attempted forced sexual activity." 
Data were analyzed using SPSS version 25. Descriptive statistics (i.e., percentages and frequencies) were compared between individuals reporting CFS, and the remaining CCHS-MH adult sample without a CFS diagnosis in terms of demographic, socioeconomic, psychiatric disorder, and other reported conditions. A series of two-factor chi-square tests were conducted to determine whether the likelihood of particular variables was depended on a CFS diagnosis.

\section{Results}

\section{Demographic and Socioeconomic Comparisons}

Of the 16,972 adult respondents in the entire CCHS-MH sample, 277 reported a diagnosis of CFS by a health professional, or 1.63 percent. As presented in Table 2 , while 70 percent of the CFS sample were female, a proportion significantly higher than that of the non-CFS sample (53.4 percent), $\chi^{2}=30.3, p<.0001$, an equivalent percentage were white, $\chi^{2}=1.1, p>.05$. In terms of age, individuals with CFS were significantly more likely to be above 44 years (69.3 vs. 47.3 percent $), \chi^{2}=61.0, p<.0001$, divorced or separated, $(27.8$ vs. 11.9 percent $) \chi^{2}=79.8, p<$ .0001 , and living within a lone-person household (42.6 vs. 26.0 percent), $\chi^{2}=51.9, p<.0001$.

An assessment of socioeconomic variables revealed that respondents reporting a CFS diagnosis were significantly more likely to also report being permanently unable to work (31.0 vs. 3.2 percent), $\chi^{2}=614.3, p<.0001$, a personal income less than $\$ 20,000$ per year (39.0 vs. 19.1 percent), $\left.\chi^{2}=123.2, p<.0001\right)$, and difficulty meeting household expenses (46.2 vs. 13.6 percent), $\chi^{2}=227.4, p<.0001$ ) (See Table 2). Despite the fact that those reporting CFS were more likely to report achieving less than secondary school (18.3 vs. 11.1 percent), $\chi^{2}=14.1, p<$ .003), there was a relatively comparable proportion reporting post-secondary graduation (i.e., 61.6 vs. 65.7 percent). 
Table 2 - Demographic and Sociodemographic Percentages and Frequencies of Individuals Reporting and Not Reporting a Diagnosis of Chronic Fatigue Syndrome (CFS)

\begin{tabular}{|c|c|c|c|c|}
\hline & Pel & ntage $(n)$ & & \\
\hline & $\begin{array}{l}\text { CFS Sample } \\
(\mathrm{n}=277)\end{array}$ & $\begin{array}{l}\text { CCHS Adult Sample } \\
\quad(n=16,682)\end{array}$ & $x^{2}$ & $\mathrm{p}$ \\
\hline Sex & & & 30.3 & $<.0001$ \\
\hline Male & $30.0(83)$ & $46.6(7771)$ & & \\
\hline Female & $70.0(194)$ & $53.4(8911)$ & & \\
\hline Race (White) & $86.3(229)$ & $83.4(13475)$ & 1.1 & ns \\
\hline Age (years) & & & 61.0 & $<.0001$ \\
\hline $20-34$ & $15.6(43)$ & $32.6(5,431)$ & & \\
\hline $35-44$ & $14.9(42)$ & $20.2(3375)$ & & \\
\hline $45-54$ & $28.9(80)$ & $21.3(3543)$ & & \\
\hline $55-64$ & $40.4(112)$ & $26.0(4333)$ & & \\
\hline Marital status & & & 79.8 & $<.0001$ \\
\hline Married & $33.6(93)$ & $44.3(7380)$ & & \\
\hline Common-law & $6.9(19)$ & $121.2(2042)$ & & \\
\hline Widowed & $4.7(13)$ & $2.1(346)$ & & \\
\hline Divorced/separated & $27.8(77)$ & $11.9(1978)$ & & \\
\hline Single & $27.1(75)$ & $29.4(4893)$ & & \\
\hline One person in household & $42.6(118)$ & $26.0(4330)$ & 51.9 & $<.0001$ \\
\hline Education & & & 14.1 & .003 \\
\hline Less than secondary school & $18.3(50)$ & $11.1(1850)$ & & \\
\hline Secondary school graduation & $14.3(39)$ & $16.7(2781)$ & & \\
\hline Some post-secondary & $5.8(16)$ & $6.4(1066)$ & & \\
\hline Post-secondary graduation & $61.6(168)$ & $65.7(10926)$ & & \\
\hline Personal income & & & 123.2 & $<.0001$ \\
\hline Less than $\$ 10,000$ & $5.1(13)$ & $6.0(930)$ & & \\
\hline$\$ 10,00-\$ 19,999$ & $33.9(86)$ & $13.1(2011)$ & & \\
\hline$\$ 20,000-\$ 29,999$ & $28.7(73)$ & $20.4(3132)$ & & \\
\hline$\$ 30,000-\$ 39,999$ & $9.4(24)$ & $13.3(2053)$ & & \\
\hline$\$ 40,000-\$ 49,999$ & $4.3(11)$ & $11.4(1761)$ & & \\
\hline$\$ 50,000$ or more & $18.5(47)$ & $35.4(5436)$ & & \\
\hline Employment Status & & & 614.3 & $<.0001$ \\
\hline Did not have a job & $30.3(83)$ & $22.4(3728)$ & & \\
\hline Permanently unable to work & $31.0(84)$ & $3.2(531)$ & & \\
\hline Difficulty meeting household expenses & $46.2(127)$ & $13.6(2253)$ & 237.4 & $<.0001$ \\
\hline
\end{tabular}




\section{Psychiatric Disorders}

Table 3 presents the proportion and frequency with which individuals with and without a

CFS diagnosis meet the CIDI criteria for lifetime and current (12-month) psychiatric diagnoses.

Table 3 - Percentage and Frequency of Psychiatric Disorders, and Reported Conditions for Individuals Reporting and Not Reporting a Diagnosis of Chronic Fatigue Syndrome (CFS)

\begin{tabular}{cccc}
\hline Percentage $(\mathrm{n})$ & & & \\
CFS Sample & CCHS Adult Sample & $\chi 2$ & $p$ \\
$(\mathrm{n}=277)$ & $(\mathrm{n}=16,682)$ &
\end{tabular}

\section{Psychiatric Disorder based on CIDI}

Life time

$\begin{array}{lcccc}\text { MDD } & 47.1(129) & 14.1(2344) & 234.1 & <.0001 \\ \text { GAD } & 45.0(122) & 11.1(1831) & 299.9 & <.0001 \\ \text { Alcohol Dependence } & 7.7(21 & 4.7(767) & 5.6 & .018 \\ \text { Cannabis Dependence } & 3.3(9) & 2.1(351) & 1.9 & n s \\ \text { Other Drug Dependence } & 6.7(18) & 2.8(455) & 15.2 & <.0001\end{array}$

12 Month

$\begin{array}{lcccc}\text { MDD } & 33.8(92) & 5.8(970) & 355.2 & <.0001 \\ \text { GAD } & 24.3(66) & 3.4(560) & 325.8 & <.0001 \\ \text { Alcohol Dependence } & 2.2(6) & 1.2(199) & 2.2 & n s \\ \text { Cannabis Dependence } & 0.4(1) & 0.6(92) & 0.7 & n s \\ \text { Other Drug Dependence } & 4.5(12) & 0.5(84) & 73.1 & <.0001\end{array}$

Reported Conditions

$\begin{array}{lcccr}\text { ADHD } & 9.8(27) & 2.8(460) & 48.0 & <.0001 \\ \text { PTSD } & 21.1(58) & 1.8(305) & 478.7 & <.0001 \\ \text { Trouble sleeping } & 61.7(171) & 15.7(2617) & 420.2 & <.0001 \\ \text { Sexual maltreatment before 16 yrs. } & 28.9(77) & 7.6(1247) & 164.3 & <.0001 \\ \text { Physical maltreatment before 16 yrs. } & 23.6(63) & 9.2(1524) & 63.3 & <.0001\end{array}$

Accordingly, respondents reporting CFS were significantly more likely to report MDD lifetime (47.1 vs. 14.1 percent), $\chi^{2}=234.1, p<.0001$, MDD 12 month (33.8 vs. 5.8 percent), $\chi^{2}=$ $355.2, p<.0001$, GAD lifetime (45.0 vs. 11.1 percent), $\chi^{2}=299.9, p<.0001$, GAD 12 month (24.3 vs. 3.4 percent), $\chi^{2}=325.8, p<.0001$, and other drug dependence lifetime (6.7 vs. 2.8 
percent), $\chi^{2}=15.2, p<.0001$, and other drug dependence 12 month (4.5 vs. 0.5$), \chi^{2}=73.1, p<$ .0001. While lifetime alcohol dependence for the CFS sample was more likely (7.7 vs. 4.7 percent), $\chi^{2}=5.6, p<.018$, cannabis dependence did not differ between the groups (See Table 3).

\section{Other Reported Conditions}

As shown in Table 3, CFS Respondents were significantly more likely to report a diagnosis of ADHD (9.8 vs. 2.8 percent), $\chi^{2}=48.0, p<.000$, and PTSD (21.1 vs. 1.8 percent), $\chi^{2}$ $=478.7, p<.0001$, as well as trouble sleeping (61.7 vs. 15.7 percent), $\chi^{2}=420.2, p<.0001$. In terms of reported childhood trauma, individuals with CFS were significantly more likely to report sexual maltreatment ( 28.9 vs. 7.6 percent), $\chi^{2}=164.3, p<.0001$, and physical maltreatment (23.6 vs. 9.2 percent), $\chi^{2}=63.3, p<.0001$.

\section{Discussion}

The objectives of the present study were to establish a demographic, socioeconomic, psychiatric, and salient experiential profile of adult Canadians with CFS, and explore how they compare to adult Canadians not reporting a CFS diagnosis. It was observed that 1.63 present of the sample of adult Canadians reported a CFS diagnosis, a percentage that falls within the spectrum of findings previously documented in the literature (i.e., between 0.2-2.6 percent of the population) $[10,39]$. It was further observed that individuals with CFS were significantly more likely to be female, between the ages of 45-64, living alone, and to divorced or separated compared to individuals without CFS. However, they were equally as likely to be white/racial minorities as individuals without CFS. Relative to previous literature, the current findings corroborate other observations in that women are significantly more likely to have a diagnosis of 
CFS $[11,12]$, and that the distribution of race is comparable in groups with and without a CFS diagnosis [16].

With respect to socioeconomic factors, it was revealed that adult Canadians with CFS were significantly more likely to be without employment or unable to work, and to have a personal income less than $\$ 20,000$, findings similar to other studies [e.g., 10, 39, 40]. Taken together, it is unsurprising that individuals with CFS were more likely to report having difficulty meeting household expenses, and while they were more likely to have achieved less than secondary school education, they were also relatively as likely to have post-secondary graduation as individuals without CFS. Notwithstanding, such findings reflect the severity of disability experienced by individuals with CFS, as they are not able to maintain full-time, or in many cases any, employment due to their health status.

Mental health characteristics. In terms of psychiatric diagnoses, it was observed that respondents reporting a CFS diagnosis were more likely to have a lifetime and 12-month diagnosis of MDD, GAD, and substance dependence, as well as lifetime alcohol dependence. Further, CFS respondents were also more likely to report ADHD, PTSD, and having experienced childhood maltreatment in the form of physical and sexual abuse. These findings are all consistent with the existing body of literature, where individuals with CFS have been found to present with significantly greater prevalence rates of psychiatric diagnoses, including mood disorders, histories of childhood trauma, PTSD, and ADHD [2, 25, 26, 27, 29, 32, 33, 34].

\section{Clinical Implications}

The discrepancies in socioeconomic status between adults with CFS and those without certainly have implications for general health status and well-being. For instance, since low socioeconomic status per se, is often associated with poorer health behaviours, particularly in 
terms of unhealthy dietary realities [e.g., 41], sedentary behaviour, healthcare interactions, and treatment adherence [e.g., 42, 43], such are certainly considerations when advocating for the optimal health of those with CFS. In addition, given significant activity limitations already experienced by individuals with CFS, it is possible that the likelihood of lower socioeconomic status could further exacerbate poor health outcomes already characteristic of this population. Lower socioeconomic status could also limit accessibility to health care services and various treatment options, as the financial realities of CFS sufferers also limit access to private sector services.

The fact that individuals with CFS are much more likely to live alone, and report being divorced or separated has also been linked with potential negative health consequences. Specifically, individuals who live alone are more likely to experience cardiac issues, mental health challenges, and even instances of higher mortality in younger age cohorts $[44,45]$. Further, it is feasible that living alone is indicative with one's sense of social isolation, with compromised access to often limited social networks which could certainly relate with poorer health outcomes $[46,47]$. As a result, future research should explore the potential health status influence that social contextual factors, such as social support, might play in the life of CFS sufferers.

Based on socioeconomic conditions alone, while it is clear that physical and behavioural concerns are quite likely, they are not to only piece of the CFS health-status puzzle. Indeed, as clearly documented in the present study, the notably high instances of psychiatric disorder diagnoses associated with CFS sufferers, including MDD, GAD, and substance dependence certainly complicate and exacerbate concerns over CFS sufferer wellbeing. Such findings speak to the importance of considering CFS as more than simply a set of physical symptoms in need of 
treatment, but also examining psychological components of symptomology and how psychological intervention may aid in alleviating symptomology [20].

The relatively high prevalence of reported PTSD and childhood maltreatment are quite striking and troubling in terms of their link with CFS. From a theoretical perspective, it is interesting to note that PTSD has been associated with a concept referred to as disorganized attachment [48]. Approximately 82 percent of children who have experienced maltreatment demonstrate disorganized attachment [49], such that they have develop a negative view of both the self and others [50], which has been further linked to lower social competence, decreased reliance on others, lower romantic involvement, and hostility in romantic relationships [50, 51]. Perhaps an indication of this might be evident in the findings herein with a higher prevalence of those with CFS living alone, and reporting being divorced or separated than individuals without CFS. Again, future research involving explorations of social factors, including distinctive relationship characteristics seems very well justified.

\section{Limitations}

While the findings of the present study provide insight into a better understanding of the CFS population as a whole, and many challenges experienced, there are several limitations to acknowledge. Firstly, the CCHS-MH sample excluded a small percentage of the population, including individuals living on Aboriginal settlements, members of the Canadian forces, and individuals that are institutionalized this limiting the generalizability of the results. Secondly, since study relied on the self-report of a CFS diagnosis by a health professional, there was no way to verify either the diagnosis, or the particular health profession providing the diagnosis. Thirdly, since participants were asked whether they had been diagnosed with CFS, there is also a chance of underreporting whereby those living CFS, but not diagnosed were excluded. 
Further, with secondary data analysis are limitation in the examination and interpretation of certain variables, such as childhood maltreatment as the measure used does not capture emotional abuse or neglect which has similar implications for physical and psychological functioning as compared with physical abuse or neglect, sexual abuse, and witnessing violence $[52,53]$

\section{Conclusions}

The results of this study have important implications for the research into, and treatment of individuals with CFS. The socioeconomic realities appear to reflect the severity of illness and poor health status of this population. Further, living alone, or being without partnership, suggests a high likelihood of social isolation, and perhaps a sense of feeling misunderstood about their illness which also may provide some insight into well-documented stigma in the literature, and mental health difficulties experienced by this population. Indeed, deficiencies in social support seem quite likely, and worthy of investigation especially given the high prevalence of childhood maltreatment histories, and comorbidity of PTSD, MDD, and GAD. 


\section{Declarations}

- Ethics approval for this study was not required as data were extracted from a publically available Public Use Microfile (PUMF) in a repository from the Data Centre, Faculty of Arts \& Sciences, University of Toronto (https://datacentre.chass.utoronto.ca/)

- Consent for publication - Not Applicable.

- The datasets generated and/or analysed during the current study are available in the Data Centre, Faculty of Arts \& Sciences, University of Toronto (https://datacentre.chass.utoronto.ca/)

- Competing interests - The authors declare that they have no competing interests.

- This research was conducted without funding.

- Authors' contributions - AR performed initial literature review, analyzed and interpreted preliminary data, and provided preliminary draft of manuscript; KF consulted on overall design, initial statistical analyses and interpretation of findings, and performed and interpreted secondary statistical analyses for manuscript development, and contributed to the drafting of final manuscript; SWF consulted on secondary statistical analyses, contributed to drafting of final manuscript, and provided support to the development of the discussion and implications of findings.

- Acknowledgements - Not applicable. 


\section{References}

1. Bested, A. C., \& Marshall, L. M. (2015). Review of myalgic encephalomyelitis/chronic fatigue syndrome: An evidence-based approach to diagnosis and management by clinicians. Reviews on Environmental Health, 30, 223-249. https://doi.org/10.1515/reveh-2015-0026

2. Bonner, D., Ron, M., Chalder, T., Butler, S., \& Wessely, S. (1994). Chronic fatigue syndrome: A follow up study. Journal of Neurology, Neurosurgery, and Psychiatry, 57, 617-621. https://doi.org/10.1136/jnnp.57.5.617

3. Carruthers, B. M., van de Sande, M. I., de Meirleir, K. L., Klimas, N. G., Broderick, G., Mitchell, T., Staines, D., Powles, A. C. P., Speight, N., Vallings, R., Bateman, L., Baumgarten-Austrheim, B., Bell, D. S., Carlo-Stella, N., Chia, J., Darragh, A., Jo, D., Lewis, D., Light, A. R., ... Stevens, S. (2011). Myalgic encephalomyelitis: International consensus criteria. Journal of Internal Medicine, 270, 327-338. https://doi.org/10.1111/j.1365-2796.2011.02428.x

4. Escobar, J., Hoyos-Nervi, C., \& Gara, M. (2002). Medically unexplained physical symptoms in medical practice: A psychiatric perspective. Environmental Health Perspectivess, 110, 631-636. https://doi.org/10.1289/ehp.02110s4631

5. Park, J., \& Knudson, S. (2007). Medically unexplained physical symptoms. Health Reports, 18, 43-47.

6. Zavestoski, S., Brown, P., McCormick, S., Mayer, B., D’Ottavi, M., \& Lucove, J. C. (2004). Patient activism and the struggle for diagnosis: Gulf War illnesses and other medically unexplained physical symptoms in the US. Social Science and Medicine, 58, 161-175. https://doi.org/10.1016/S0277-9536(03)00157-6

7. Wessely, S., \& Powell, R. (1989). Fatigue syndromes: A comparison of chronic 
"postviral” fatigue with neuromuscular and affective disorders. Journal of Neurology, Neurosurgery, and Psychiatry, 52, 940-948. https://doi.org/DOI 10.1136/jnnp.52.8.940

8. Wilson, A., Hickie, I., Lloyd, A., Hadzi-Pavlovic, D., Boughton, C., Dwyer, J., \& Wakefield, D. (1994). Longitudinal study of outcome of chronic fatigue syndrome. British Medical Journal, 308, 756-759.

9. Johnston, S., Brenu, E. W., Staines, D., \& Marshall-Gradisnik, S. (2013). The prevalence of chronic fatigue syndrome/myalgic encephalomyelitis: A meta-analysis. Clinical Epidemiology, 5, 105-110. https://doi.org/10.2147/CLEP.S39876

10. Steele, L., Dobbins, J. G., Fukuda, K., Reyes, M., Randall, B., Koppelman, M., \& Reeves, W. C. (1998). The epidemiology of chronic fatigue in San Francisco. American Journal of Medicine, 105, 83S-90S. https://doi.org/10.1016/s0002-9343(98)00158-2

11. Komaroff, A. L., \& Buchwald, D. (1991). Symptoms and signs of chronic fatigue syndrome. Reviews of Infectious Diseases, 13, S8-S11. https://doi.org/10.1093/clinids/13.Supplement_1.S8

12. Pawlikowska, T., Chalder, T., Hirsch, S. R., Wallace, P., Wright, D. J. M., \& Wessely, S. C. (1994). Population based study of fatigue and psychological distress. British Medical Journal Clinical Research, 308, 763-766. https://doi.org/10.1136/bmj.308.6931.763

13. Pendergrast, T., Brown, A., Sunnquist, M., Jantke, R., Newton, J. L., Strand, E. B., \& Jason, L. A. (2016). Housebound versus nonhousebound patients with myalgic encephalomyelitis and chronic fatigue syndrome. Chronic Illness, 12, 292-307. https://doi.org/10.1177/1742395316644770

14. Carruthers, B. M., Jain, A. K., de Meirleir, K. L., Peterson, D. L., Klimas, N. G., Lerner, A. M., Bested, A. C., Flor-Henry, P., Joshi, P., Powles, A. C. P., Sherkey, J. A., \& van de 
Sande, M. I. (2003). Myalgic encephalomyelitis/chronic fatigue syndrome: Clinical working case definition, diagnostic and treatment protocols. Journal of Chronic Fatigue Syndrome, 11, 7-97. https://doi.org/10.1300/J092v11n01_02

15. Moss-Morris, R., Petrie, K. J., \& Weinman, J. (1996). Functioning in chronic fatigue syndrome: Do illness perceptions play a regulatory role? British Journal of Health Psychology, 1, 15-25. https://doi.org/10.1111/j.2044-8287.1996.tb00488.x

16. Reeves, W. C., Jones, J. F., Maloney, E., Heim, C., Hoaglin, D. C., Boneva, R. S., Morrissey, M., \& Devlin, R. (2007). Prevalence of chronic fatigue syndrome in metropolitan, urban, and rural Georgia. Population Health Metrics, 5. https://doi.org/10.1186/1478-7954-5-5

17. Reid, S., Chalder, T., Cleare, A., Hotopf, M., Wessely, S., Fukuda, K., Straus, S., Hickie, I., Sharpe, M., Dobbins, J., Komaroff, A., Sharpe, M., Archard, L., Banatvala, J., Wessely, S., Chalder, T., Hirsch, S., Wallace, P., Wright, D., ... Bellanti, J. (2000). Chronic fatigue syndrome. BMJ, 320, 292-296. https://doi.org/10.1136/bmj.320.7230.292

18. Holmes, G. P., Kaplan, J. E., Gantz, N. M., Komaroff, A. L., Schonberger, L. B., Straus, S. E., Jones, J. F., Dubois, R. E., Cunningham-Rundles, C., Pahwa, S., \& Al, E. (1988). Chronic fatigue syndrome: A working case definition. Annals of Internal Medicine, 108, 387-389. https://doi.org/10.7326/0003-4819-108-3-387

19. American Psychiatric Association. (2013). Diagnostic and statistical manual of mental disorders, fifth edition. American Psychiatric Association. https://doi.org/10.1176/appi.books.9780890425596.744053

20. Stewart, D. E. (1990). The changing faces of somatization. Psychosomatics, 31, 153-158. 
https://doi.org/10.1016/S0033-3182(90)72188-3

21. Wessely, S. (1995a). Social and cultural aspects of chronic fatigue syndrome. Journal of Musculoskeletal Pain, 3, 111-122. https://doi.org/10.1300/J094v03n02

22. Twisk, F. N. M. (2014). The status of and future research into myalgic encephalomyelitis and chronic fatigue syndrome: The need of accurate diagnosis, objective assessment, and acknowledging biological and clinical subgroups. Frontiers in Psychology, 5. https://doi.org/10.3389/fphys.2014.00109

23. Esfandyarpour, R., Kashi, A., Nemat-Gorgani, M., Wilhelmy, J., \& Davis, R. W. (2019). A nanoelectronics-blood-based diagnostic biomarker for myalgic encephalomyelitis/chronic fatigue syndrome (ME/CFS). Proceedings of the National Academy of Sciences of the United States of America, 116, 10250-10257. https://doi.org/10.1073/pnas.1901274116

24. Scheeres, K., Wensing, M., Severens, H., Adang, E., \& Bleijenberg, G. (2008).

Determinants of health care use in chronic fatigue syndrome patients: A cross-sectional study. Journal of Psychosomatic Research, 65, 39-46. https://doi.org/10.1016/j.jpsychores.2008.03.015

25. Wessely, S., Chalder, T., Hirsch, S., Wallace, P., \& Wright, D. (1996). Psychological symptoms, somatic symptoms, and psychiatric disorder in chronic fatigue and chronic fatigue syndrome: A prospective study in the primary care setting. American Journal of Psychiatry, 153, 1050-1059.

26. McInnis, O. A., Matheson, K., \& Anisman, H. (2014). Living with the unexplained: Coping, distress, and depression among women with chronic fatigue syndrome and/or fibromyalgia compared to an autoimmune disorder. Anxiety, Stress \& Coping, 27, 601- 
618. https://doi.org/10.1080/10615806.2014.888060

27. Heim, C., Wagner, D., Maloney, E., Papanicolaou, D. A., Solomon, L., Jones, J. F., Unger, E. R., \& Reeves, W. C. (2006). Early adverse experience and risk for chronic fatigue syndrome: Results from a population-based study. Archives of General Psychiatry, 63, 1258-1266. https://doi.org/10.1001/archpsyc.63.11.1258

28. Nater, U. M., Maloney, E., Heim, C., \& Reeves, W. C. (2011). Cumulative life stress in chronic fatigue syndrome. Psychiatry Research, 189, 318-320. https://doi.org/10.1016/j.psychres.2011.07.015

29. Kempke, S., Luyten, P., Claes, S., Van Wambeke, P., Bekaert, P., Goossens, L., \& Van Houdenhove, B. (2013). The prevalence and impact of early childhood trauma in chronic fatigue syndrome. Journal of Psychiatric Research, 47, 664-669. https://doi.org/10.1016/j.jpsychires.2013.01.021

30. Krzeczkowska, A., Karatzias, T., \& Dickson, A. (2015). Pain in people with chronic fatigue syndrome/myalgic encephalomyelitis: The role of traumatic stress and coping strategies. Psychology, Health \& Medicine, 20, 210-216.

https://doi.org/10.1080/13548506.2014.951370

31. van Houdenhove, B., Luyten, P., \& Egle, U. T. (2009). Stress as a key concept in chronic widespread pain and fatigue disorders. Journal of Musculoskeletal Pain, 17, 390-399. https://doi.org/10.3109/10582450903284745

32. Janssens, K. A. M., Zijlema, W. L., Joustra, M. L., \& Rosmalen, J. G. M. (2015). Mood and anxiety disorders in chronic fatigue syndrome, fibromyalgia, and irritable bowel syndrome: Results from the lifelines cohort study. Psychosomatic Medicine, 77, 449-457. https://doi.org/10.1097/PSY.0000000000000161 
33. Mariman, A., Delesie, L., Tobback, E., Hanoulle, I., Sermijn, E., Vermeir, P., Pevernagie, D., \& Vogelaers, D. (2013). Undiagnosed and comorbid disorders in patients with presumed chronic fatigue syndrome. Journal of Psychosomatic Research, 75, 491-496. https://doi.org/10.1016/j.jpsychores.2013.07.010

34. Sáez-Francàs, N., Valero, S., Calvo, N., Gomà-I-Freixanet, M., Alegre, J., de Sevilla, T. F., \& Casas, M. (2014). Chronic fatigue syndrome and personality: A case-control study using the alternative five factor model. Psychiatry Research, 216, 373-378. https://doi.org/10.1016/j.psychres.2014.02.031

35. Statistics Canada. (2013). Canadian Community Health Survey (CCHS)_Mental health user guide.

36. American Psychiatric Association. (1994). Diagnostic and statistical manual of mental disorders (4th ed.). Washington, DC: Author.

37. World Health Organization. (1992). International classification of diseases and related health problems (10th rev.). Geneva: World Health Organization.

38. Walsh, C. A., MacMillan, H. L., Trocmé, N., Jamieson, E., \& Boyle, M. H. (2008). Measurement of victimization in adolescence: Development and validation of the Childhood Experiences of Violence Questionnaire. Child Abuse \& Neglect, 32, 10371057. https://doi.org/10.1016/j.chiabu.2008.05.003

39. Wessely, S., Chalder, T., Hirsch, S., Wallace, P., \& Wright, D. (1997). The prevalence and morbidity of chronic fatigue and chronic fatigue syndrome: A prospective primary care study. American Journal of Public Health, 87, 1449-1455. https://doi.org/10.2105/AJPH.87.9.1449

40. Jason, L. A., Benton, M. C., Valentine, L., Johnson, A., \& Torres-Harding, S. (2008). 
The economic impact of ME/CFS: Individual and societal costs. Dynamic Medicine, 7. https://doi.org/10.1186/1476-5918-7-6

41. Lagström, H., Halonen, J. I., Kawachi, I., Stenholm, S., Pentti, J., Suominen, S., Kivimäki, M., \& Vahtera, J. (2019). Neighborhood socioeconomic status and adherence to dietary recommendations among Finnish adults: A retrospective follow-up study. Health and Place, 55, 43-50. https://doi.org/10.1016/j.healthplace.2018.10.007

42. Sahekbar, M., Heidarian Miri, H., Noormohammadpour, P., Akrami, R., Mansournia, N., Tavana, B., Mansournia, M. A., \& Stamatakis, E. (2018). Prevalence and correlates of low physical activity in the Iranian population: National survey on non-communicable diseases in 2011. Scandinavian Journal of Medicine \& Science in Sports, 28, 1916-1924. https://doi.org/10.1111/sms.13082

43. Sninsky, B. C., Nakada, S. Y., \& Penniston, K. L. (2015). Does socioeconomic status, age, or gender influence appointment attendance and completion of 24-hour urine collections? Urology, 85, 568-573. https://doi.org/10.1016/j.urology.2014.10.043

44. O’Keefe, J., Torres-Acosta, N., \& Lavie, C. J. (2019). Living alone makes the heart more vulnerable. Heart, 106, 246-247. https://doi.org/10.1136/heartjnl-2019-316042

45. Tamminen, N., Kettunen, T., Martelin, T., Reinikainen, J., \& Solin, P. (2019). Living alone and positive mental health: A systematic review. BMC, 8 . https://doi.org/10.1186/s13643-019-1057-x

46. Holt-Lunstad, J., Smith, T. B., \& Layton, J. B. (2010). Social relationships and mortality risk: A meta-analytic review. PLOS Medicine, 7. https://doi.org/10.1371/journal.pmed.1000316

47. Sakurai, R., Kawai Phd, H., Suzuki, H., Kim Phd, H., Watanabe, Y., Hirano, H., Pt, O., \& 
Fujiwara, Y. (2019). Poor social network, not living alone, is associated with incidence of adverse health outcomes in older adults. JAMDA, 20, 1438-1443.

https://doi.org/10.1016/j.jamda.2019.02.021

48. O’Connor, M., \& Elklit, A. (2008). Attachment styles, traumatic events, and PTSD: A cross-sectional investigation of adult attachment and trauma. Attachment and Human Development, 10, 59-71. https://doi.org/10.1080/14616730701868597

49. Carlson, V., Cicchetti, D., Barnett, D., \& Braunwald, K. (1989). Disorganized/disoriented attachment relationships in maltreated infants. Developmental Psychology, 25, 525-531. https://doi.org/10.1037/0012-1649.25.4.525

50. Bartholomew, K., \& Horowitz, L. M. (1991). Attachment styles among young adults: A test of a four-category model. Journal of Personality and Social Psychology, 61, 226244. https://doi.org/10.1037/0022-3514.61.2.226

51. Sroufe, L. A. (2005). Attachment and development: A prospective, longitudinal study from birth to adulthood. Attachment and Human Development, 7, 349-367. https://doi.org/10.1080/14616730500365928

52. Spertus, I. L., Yehuda, R., Wong, C. M., Halligan, S., \& Seremetis, S. V. (2003). Childhood emotional abuse and neglect as predictors of psychological and physical symptoms in women presenting to a primary care practice. Child Abuse and Neglect, 27, 1247-1258. https://doi.org/10.1016/j.chiabu.2003.05.001

53. Zurbriggen, E. L., Gobin, R. L., \& Freyd, J. J. (2010). Childhood emotional abuse predicts late adolescent sexual aggression perpetration and victimization. Journal of Aggression, Maltreatment and Trauma, 19, 204-223. https://doi.org/10.1080/10926770903539631 
54. Holmes, G. P., Kaplan, J. E., Gantz, N. M., Komaroff, A. L., Schonberger, L. B., Straus, S. E., Jones, J. F., Dubois, R. E., Cunningham-Rundles, C., Pahwa, S., \& Al, E. (1988). Chronic fatigue syndrome: A working case definition. Annals of Internal Medicine, 108, 387-389. https://doi.org/10.7326/0003-4819-108-3-387

55. Fukuda, K., Straus, S. E., Hickie, I., Sharpe, M. C., Dobbins, J. G., \& Komaroff, A. (1994). The chronic fatigue syndrome: A comprehensive approach to its definition and study. Annals of Internal Medicine, 121, 953-959.

56. Carruthers, B. M., Jain, A. K., de Meirleir, K. L., Peterson, D. L., Klimas, N. G., Lerner, A. M., Bested, A. C., Flor-Henry, P., Joshi, P., Powles, A. C. P., Sherkey, J. A., \& van de Sande, M. I. (2003). Myalgic encephalomyelitis/chronic fatigue syndrome: Clinical working case definition, diagnostic and treatment protocols. Journal of Chronic Fatigue Syndrome, 11, 7-97. https://doi.org/10.1300/J092v11n01_02 